\title{
The Effect of Hydrogen Sulfide Concentration on Gel as Water Shutoff Agent
}

\author{
Q. You ${ }^{1,2 *}$, L. Mu' ${ }^{2}$, Y. Wang ${ }^{2}$ and F. Zhao ${ }^{2}$ \\ 1 Institute of Oil \& Gas, Peking University, \\ 2 School of Petroleum Engineering, China University of Petroleum, \\ e-mail: youging@pku.edu.cn - mulina1982@yahoo.com.cn - yfwang@upc.edu.cn - prodchem@upc.edu.cn \\ * Corresponding author
}

Résumé - Effet de la concentration en sulfure d'hydrogène sur un gel utilisé en tant qu'agent de traitement des venues d'eaux - Pour le forage et le traitement des venues d'eau dans des réservoirs d'huile et de gaz contenant du sulfure d'hydrogène $\left(\mathrm{H}_{2} \mathrm{~S}\right)$, les effets de l' $\mathrm{H}_{2} \mathrm{~S}$ sur les gels couramment utilisés pour le traitement des venues d'eau sont étudiés. Les gels incluent un gel de $\mathrm{Na}_{2} \mathrm{Cr}_{2} \mathrm{O}_{7} / \mathrm{Na}_{2} \mathrm{SO}_{3} / \mathrm{HPAM}$, un gel de $\mathrm{Na}_{2} \mathrm{Cr}_{2} \mathrm{O}_{7} /\left(\mathrm{NH}_{2}\right)_{2} \mathrm{CS} / \mathrm{HPAM}$, un gel d'acétate de $\mathrm{Cr}(\mathrm{III})$ \& lactate de $\mathrm{Cr}(\mathrm{III}) / \mathrm{HPAM}$ et un gel à base de résine de phénol formaldéhyde/HPAM. Les résultats montrent que :

- pour un gel de $\mathrm{Na}_{2} \mathrm{Cr}_{2} \mathrm{O}_{7} / \mathrm{Na}_{2} \mathrm{SO}_{3} / \mathrm{HPAM}$ et un gel de $\mathrm{Na}_{2} \mathrm{Cr}_{2} \mathrm{O}_{7} /\left(\mathrm{NH}_{2}\right)_{2} \mathrm{CS} / \mathrm{HPAM}, \mathrm{l}_{2} \mathrm{H}_{2} \mathrm{~S}$ en tant qu'agent réducteur (la réductibilité est plus efficace que celle du $\mathrm{Na}_{2} \mathrm{SO}_{3}$ et du $\left(\mathrm{NH}_{2}\right)_{2} \mathrm{CS}$ ) peut réduire le $\mathrm{Cr}(\mathrm{VI})$ en $\mathrm{Cr}(\mathrm{III})$ et accélérer la réaction de réticulation avec le HPAM en présence d'une faible concentration en $\mathrm{H}_{2} \mathrm{~S}$, tandis qu'il peut réagir avec le $\mathrm{Cr}(\mathrm{III})$ en produisant un précipité de $\mathrm{Cr}_{2} \mathrm{~S}_{3}$ en présence d'une concentration élevée en $\mathrm{H}_{2} \mathrm{~S}$, ce pour quoi le gel en masse ne peut se former sans $\mathrm{Cr}$ (III) ;

- pour un gel d'acétate de $\mathrm{Cr}(\mathrm{III})$ \& lactate de $\mathrm{Cr}(\mathrm{III}) / \mathrm{HPAM}, \mathrm{H}_{2} \mathrm{~S}$ peut prolonger le temps de gélification et réduire la résistance du gel par diminution de la valeur $\mathrm{du} \mathrm{pH}$;

- pour un gel à base de résine de phénol formaldéhyde/HPAM, $\mathrm{H}_{2} \mathrm{~S}$ peut prolonger légèrement le temps de gélification et réduire légèrement la résistance du gel par diminution de la valeur $\mathrm{du} \mathrm{pH}$. De ce fait, selon les études complètes des effets de l' $\mathrm{H}_{2} \mathrm{~S}$ sur des gels utilisés en tant qu'agent pour le traitement des venues d'eau, le gel de résine de phénol formaldéhyde/HPAM est recommandé dans les réservoirs d'huile and gaz contenant de $\mathrm{l}^{\prime} \mathrm{H}_{2} \mathrm{~S}$.

Abstract - The Effect of Hydrogen Sulfide Concentration on Gel as Water Shutoff Agent - For drilling and water shutoff of oil and gas reservoirs containing hydrogen sulfide $\left(\mathrm{H}_{2} \mathrm{~S}\right)$, the effects of $\mathrm{H}_{2} \mathrm{~S}$ on widely used gel as water shutoff agents are studied. The gels include $\mathrm{Na}_{2} \mathrm{Cr}_{2} \mathrm{O}_{7} / \mathrm{Na}_{2} \mathrm{SO}_{3} / \mathrm{HPAM}$ gel, $\mathrm{Na}_{2} \mathrm{Cr}_{2} \mathrm{O}_{7} /\left(\mathrm{NH}_{2}\right)_{2} \mathrm{CS} / \mathrm{HPAM}$ gel, $\mathrm{Cr}$ (III)-acetate \& $\mathrm{Cr}$ (III)-lactate/HPAM gel and phenol formaldehyde resin/HPAM gel. The results show that:

- for $\mathrm{Na}_{2} \mathrm{Cr}_{2} \mathrm{O}_{7} / \mathrm{Na}_{2} \mathrm{SO}_{3} / \mathrm{HPAM}$ gel and $\mathrm{Na}_{2} \mathrm{Cr}_{2} \mathrm{O}_{7} /\left(\mathrm{NH}_{2}\right)_{2} \mathrm{CS} / \mathrm{HPAM}$ gel, the $\mathrm{H}_{2} \mathrm{~S}$ as reducing agent (the reducibility is more efficient than that of $\mathrm{Na}_{2} \mathrm{SO}_{3}$ and $\left(\mathrm{NH}_{2}\right)_{2} \mathrm{CS}$ ) can reduce $\mathrm{Cr}$ (VI) into $\mathrm{Cr}$ (III) and accelerate crosslinking reaction with HPAM in low concentration of $\mathrm{H}_{2} \mathrm{~S}$, while it can react with $\mathrm{Cr}(I I I)$ generating $\mathrm{Cr}_{2} \mathrm{~S}_{3}$ precipitation in high concentration of $\mathrm{H}_{2} \mathrm{~S}$, for which the bulk gel can not form without $\mathrm{Cr}(\mathrm{III})$;

- for Cr(III)-acetate \& $\mathrm{Cr}(\mathrm{III})$-lactate/HPAM gel, $\mathrm{H}_{2} \mathrm{~S}$ can prolong the gelation time and reduce the gel strength by decreasing $\mathrm{pH}$ value;

- for phenol formaldehyde resin/HPAM gel, $\mathrm{H}_{2} \mathrm{~S}$ can slightly prolong the gelation time and slightly reduce the gel strength by decreasing $\mathrm{pH}$ value. Therefore, according to the comprehensive investigations of the effects of $\mathrm{H}_{2} \mathrm{~S}$ on gel as water shutoff agents, the phenol formaldehyde resin/HPAM gel is recommended as the water shutoff agents suitable for oil and gas reservoir containing $\mathrm{H}_{2} \mathrm{~S}$. 


\section{INTRODUCTION}

$\mathrm{H}_{2} \mathrm{~S}$ frequently appeared in oil and gas reservoir which can lead to problems usually met in drilling, workover, oil and gas production. For example, in the Northeast Sichuan of China, the leak, kick and blowout of gas well containing $\mathrm{H}_{2} \mathrm{~S}$ were solved using gel materials in in the process of drilling and workover (Xunyong Nie, 2006; Jianjun Wang, 2005). Some gasfields containing $\mathrm{H}_{2} \mathrm{~S}$ are seriously affected by an excessive water production. At the present time, gas recovery by discharging water is used to solve the problem all over the world (Jiyong Zhou, 2005). If the gas wells with producing water can be directly solved by water shutoff technology, it will not only reduce costs and increase the economic efficiency, but it will also avoid the problems of the treatment of large amount of produced water, of production of sands and of the corrosion of pipeline. Some oilfields also encounter some $\mathrm{H}_{2} \mathrm{~S}$ related problems, such as Zhanarol (Russian name) oilfield in caspian offshore basin of Kazakhstan. For this huge and complex fractured carbonate reservoir, it is extremely urgent to carry out water shutoff for the well which has a high water cut. However, from 2002 to 2006, the effectiveness of chemical water plugging treatment was very low. In addition to the water shutoff troubles, there exists other problems related to the high concentration of $\mathrm{H}_{2} \mathrm{~S}$, which is about 600 1000 mg/L. Gels as water shutoff agents are widely used due to their low price, easy preparation and injection, good applicability. At the present time, there are no studies on how $\mathrm{H}_{2} \mathrm{~S}$ affects gel used as water shutoff agents: it was necessary to study this aspect based on the reservoir conditions of Zhanarol oilfield.

\section{DESCRIPTION AND APPLICATION OF EQUIPMENT AND PROCESSES}

\subsection{Drugs and Reagents}

HPAM: HPAM is purchased from Yuguang Company: its viscosity-average molecular weight is $1.6 \times 10^{7}$, degree of hydrolysis is $24.4 \%$, and solid content is $90.9 \%$.

Crosslinker: two inorganic chromium crosslinkers from Yuguang company, one is a complex of $\mathrm{Na}_{2} \mathrm{Cr}_{2} \mathrm{O}_{7} / \mathrm{Na}_{2} \mathrm{SO}_{3}$, another one is a complex of $\mathrm{Na}_{2} \mathrm{Cr}_{2} \mathrm{O}_{7} /\left(\mathrm{NH}_{2}\right)_{2} \mathrm{CS}$ are used. YG107 from Yuguang company is an organic chromium crosslinker, it is a complex of $\mathrm{Cr}$ (III)-acetate and $\mathrm{Cr}$ (III)lactate. YG103 also from Yuguang Company is a phenol formaldehyde resin crosslinker.

Chemical reagents: $\mathrm{H}_{2} \mathrm{~S}$ (analytical reagent) from Beijing Multi Technology Company is used. Hydrochloric acid (analytical reagent), dimethylamino aniline hydrochloride (analytical reagent), iron trichloride (analytical reagent), ammonium dihydrogen phosphate (analytical reagent) and zinc acetate (analytical reagent) come from Beijing chemical reagents company.
TABLE 1

The composition of simulation produced water $(\mathrm{mg} / \mathrm{L})$

\begin{tabular}{c|c|c|c|c|c|c|c}
\hline Components & $\mathrm{Na}^{+}+\mathrm{K}^{+}$ & $\mathrm{Ca}^{2+}$ & $\mathrm{Mg}^{2+}$ & $\mathrm{HCO}_{3}^{-}$ & $\mathrm{CO}_{3}^{2-}$ & $\mathrm{SO}_{4}^{2-}$ & $\mathrm{Cl}^{-}$ \\
\hline Concentration $(\mathrm{mg} / \mathrm{L})$ & 8272.7 & 1120.0 & 192.0 & 784.5 & 44.1 & 762.2 & 14146.3 \\
\hline
\end{tabular}

Brine: the simulation produced water is prepared according to the Zhanarol oilfield composition, its total salinity is $25321.8 \mathrm{mg} / \mathrm{L}$ and $\mathrm{pH}$ value is 6.53 . The water composition is shown in Table 1.

\subsection{Test Equipment}

A pHS-25 digital $\mathrm{pH}$ meter is used to measure the $\mathrm{pH}$ value of the solution. SX721 digital spectrophotometer is used to determine the concentration of $\mathrm{H}_{2} \mathrm{~S}$ in the simulation produced water. BS423S balance is used to weigh materials. ICP (Inductively Coupled Plasma emission spectrometer) permits to measure the concentration of chromium and sulfur in the solution. An electric centrifuge is used to centrifugate the solution in order to separate the supernatants and the precipitates from the solution.

\subsection{Test Method}

\subsubsection{Preparation Method of Simulation Produced Water Containing $\mathrm{H}_{2} \mathrm{~S}$}

$\mathrm{H}_{2} \mathrm{~S}$ is a very toxic gas, its solubility is not easy to detect directly. The following method is used to prepare simulation produced water containing $\mathrm{H}_{2} \mathrm{~S}$ : in the fumed cupboard, connect the conical beaker filling simulation produced water with $\mathrm{H}_{2} \mathrm{~S}$ containing gas cylinders, open the valve of $\mathrm{H}_{2} \mathrm{~S}$ gas cylinders, pump $\mathrm{H}_{2} \mathrm{~S}$ into conical beaker for a time, then close the valve and make $\mathrm{H}_{2} \mathrm{~S}$ dissolve in equilibrium, using the methylene blue method (SY/T 5329-94, 1995, this is one of Chinese oil and gas industry standards) to determine the concentration of $\mathrm{H}_{2} \mathrm{~S}$ in the simulation produced water. The concentrations of $\mathrm{H}_{2} \mathrm{~S}$ range from $0 \mathrm{mg} / \mathrm{L}$ to $3700 \mathrm{mg} / \mathrm{L}$.

\subsubsection{Preparation Method of Gelants Containing $\mathrm{H}_{2} \mathrm{~S}$}

Simulated produced water without containing $\mathrm{H}_{2} \mathrm{~S}$ was used to prepare a $0.6 \%$ HPAM solution, the gelants were prepared by adding crosslinker and simulated produced water containing $\mathrm{H}_{2} \mathrm{~S}$ used to dilute $0.6 \%$ HPAM into $0.5 \%$ HPAM. At the same time, the concentration of $\mathrm{H}_{2} \mathrm{~S}$ in gelants is calculated. Then put HPAM solution and crosslinker into sealed glass bottle and mixed them, then put them into oven at the temperature of $60^{\circ} \mathrm{C}$ until the gel is fully formed (according to Sydansk's method (Sydansk, 1988)).

\subsubsection{The Testing Method of Gelation Time}

The gelants composed of HPAM and different crosslinker are put into an oven at the temperature of $60^{\circ} \mathrm{C}$ until the gel is 
fully formed. Gelation time is when the gelants change from code A into code G according to the Sydansk's method (Sydansk, 1988). Code A refers to the state that continuous gel can not be detected and the viscosity of gelants is the same than the polymer solution. Code $\mathrm{G}$ refers to the state that continuous gel can be detected and gel will become deformed and increase about half of its height when the sealed glass bottle is turned upside down.

\subsubsection{The testing Method of Gel Strength}

Breakthrough vacuum method (Caili Dai, 2001) is used to determine the gel strength. The measurement device is shown in Figure 1. Its principle is that the gel strength is measured by using the pressure difference between atmospheric pressure and the pressure of safety bottle. It has to be corrected in order to separately determine water-based and oil-based water shutoff agent by water and glycerol before using it. The breakthrough vacuum values of water and glycerol are $0.007 \mathrm{MPa}$ and $0.028 \mathrm{MPa}$ separately.

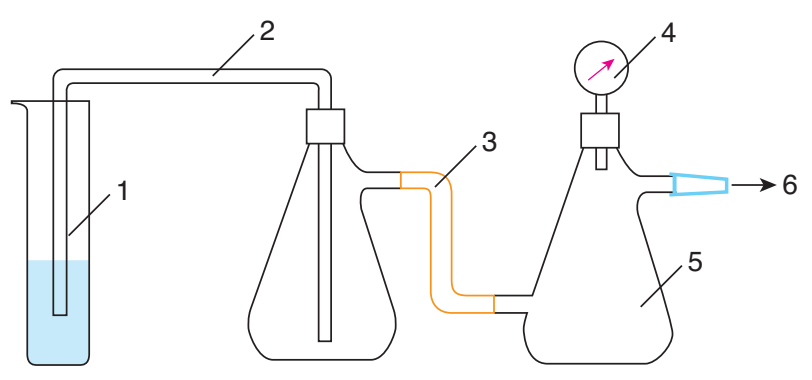

Figure 1

The determination installation of breakthrough vacuum method (Caili Dai, 2001).

1: Colorcomparison tube; 2: U-tube; 3: rubber tube; 4: pressure gauge; 5 : safety bottle; 6 : vacuum pump.

\section{RESULTS AND DISCUSSION}

\subsection{The effect of $\mathrm{H}_{2} \mathrm{~S}$ on Inorganic Chromium Crosslinking Gelants}

The composition of two inorganic chromium crosslinking gelants named $1^{\#}$ and $2^{\#}$ are shown in Table 2. Figures 2-5 show that the results of $\mathrm{H}_{2} \mathrm{~S}$ effect on two inorganic chromium crosslinking gel. The $X$ axis is $\mathrm{H}_{2} \mathrm{~S}$ concentration and the $Y$ is gelation time/gel strength. It can be seen that the effect of $\mathrm{H}_{2} \mathrm{~S}$ on inorganic chromium crosslinking gel was significant. When the concentration of $\mathrm{H}_{2} \mathrm{~S}$ was smaller than $100 \mathrm{mg} / \mathrm{L}$, the gelation time decreased rapidly with the concentration of $\mathrm{H}_{2} \mathrm{~S}$, and the gel strength increases. But when the concentration of $\mathrm{H}_{2} \mathrm{~S}$ was higher $\left(1^{\#}\right.$ was higher
TABLE 2

Composition of the gelants

\begin{tabular}{c|c}
\hline No. & Composition of the gelants \\
\hline $1^{\#}$ & $0.5 \% \mathrm{HPAM}+0.2 \% \mathrm{Na}_{2} \mathrm{Cr}_{2} \mathrm{O}_{7}+0.4 \% \mathrm{Na}_{2} \mathrm{SO}_{3}$ \\
\hline $2^{\#}$ & $0.5 \% \mathrm{HPAM}+0.2 \% \mathrm{Na}_{2} \mathrm{Cr}_{2} \mathrm{O}_{7}+0.4 \%\left(\mathrm{NH}_{2}\right)_{2} \mathrm{CS}$ \\
\hline $3^{\#}$ & $0.2 \% \mathrm{Na}_{2} \mathrm{Cr}_{2} \mathrm{O}_{7}+0.4 \% \mathrm{Na}_{2} \mathrm{SO}_{3}$ \\
\hline $4^{\#}$ & $0.2 \% \mathrm{Na}_{2} \mathrm{Cr}_{2} \mathrm{O}_{7}+0.4 \%\left(\mathrm{NH}_{2}\right)_{2} \mathrm{CS}$ \\
\hline $5^{\#}$ & $0.5 \% \mathrm{HPAM}+0.4 \% \mathrm{YG107}$ \\
\hline $6^{\#}$ & $0.5 \% \mathrm{HPAM}+1.2 \% \mathrm{YG103}$ \\
\hline
\end{tabular}

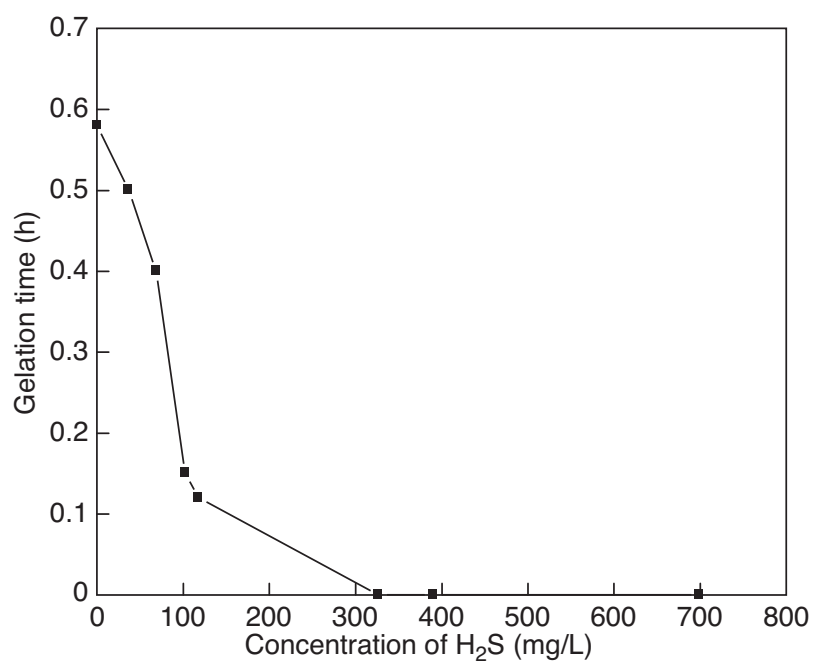

Figure 2

The effect of $\mathrm{H}_{2} \mathrm{~S}$ on the gelation time of $\mathrm{Na}_{2} \mathrm{Cr}_{2} \mathrm{O}_{7} / \mathrm{Na}_{2} \mathrm{SO}_{3} / \mathrm{HPAM}$ gel.

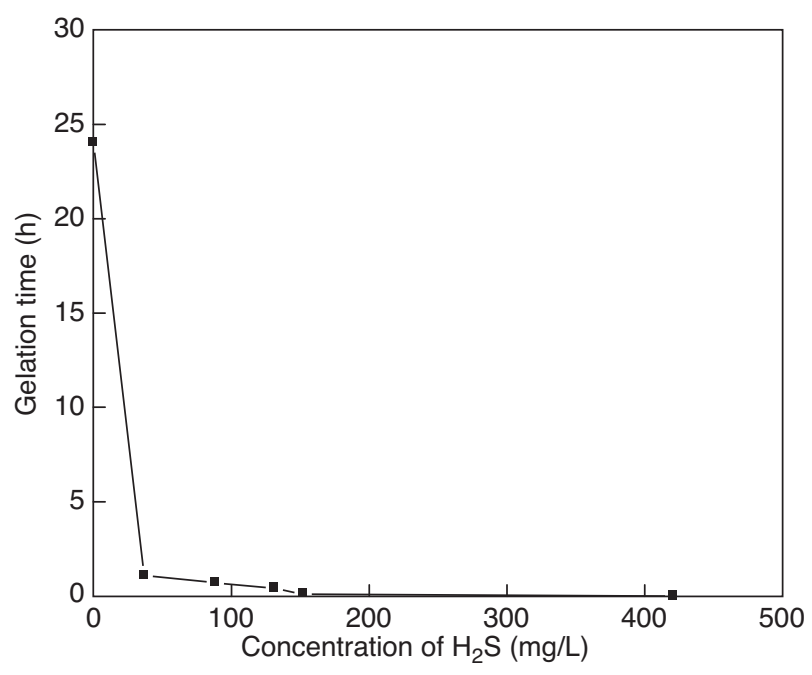

Figure 3

The effect of $\mathrm{H}_{2} \mathrm{~S}$ on the gelation time of $\mathrm{Na}_{2} \mathrm{Cr}_{2} \mathrm{O}_{7} /\left(\mathrm{NH}_{2}\right)_{2} \mathrm{CS} / \mathrm{HPAM}$ gel. 


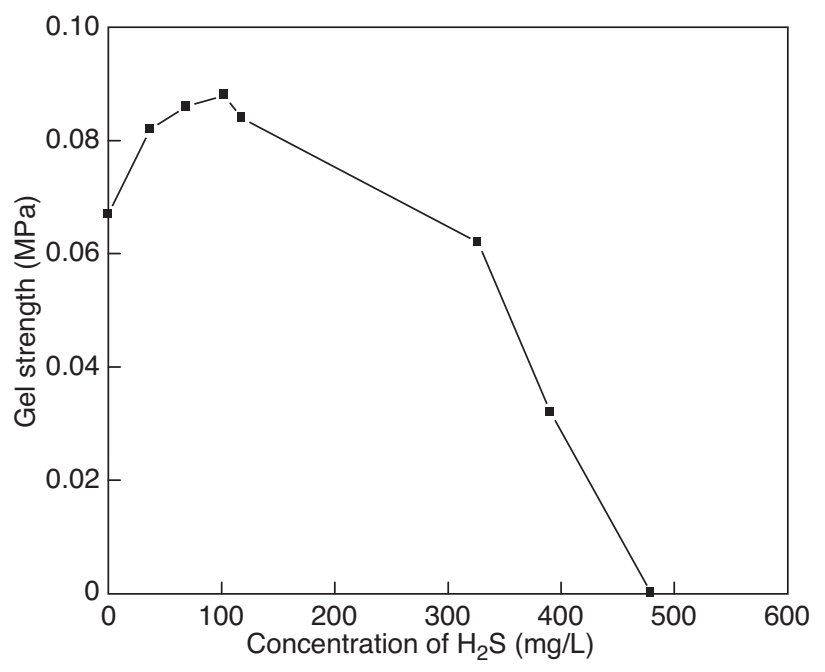

Figure 4

The effect of $\mathrm{H}_{2} \mathrm{~S}$ on the gel strength of $\mathrm{Na}_{2} \mathrm{Cr}_{2} \mathrm{O}_{7} / \mathrm{Na}_{2} \mathrm{SO}_{3} / \mathrm{HPAM}$ gel.

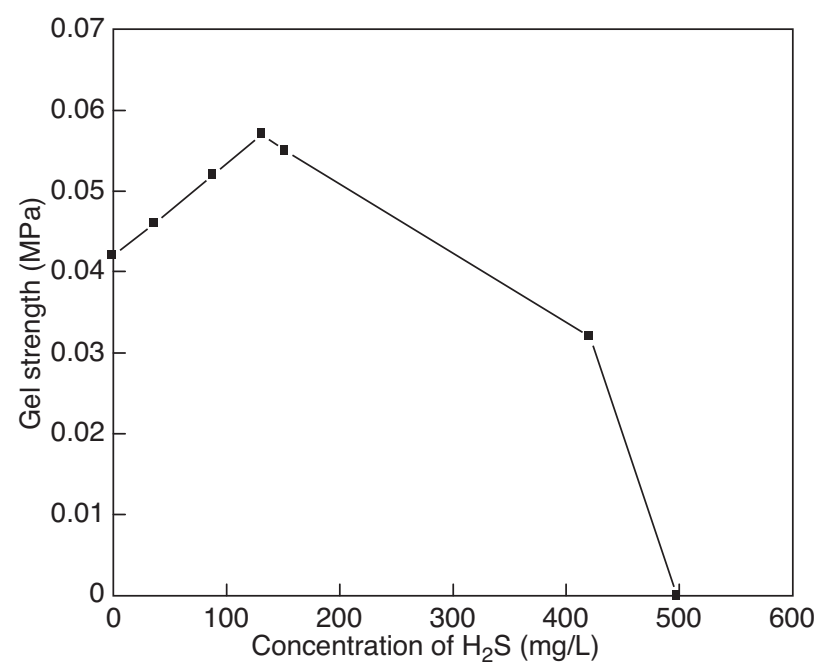

Figure 5

The effect of $\mathrm{H}_{2} \mathrm{~S}$ on the gel strength of $\mathrm{Na}_{2} \mathrm{Cr}_{2} \mathrm{O}_{7} /\left(\mathrm{NH}_{2}\right)_{2} \mathrm{CS} / \mathrm{HPAM}$ gel.

than $390 \mathrm{mg} / \mathrm{L}, 2^{\#}$ was higher than $420 \mathrm{mg} / \mathrm{L}$ ), the gelants only formed a blue small mass jelly and didn't form bulk gel.

In two inorganic chromium crosslinking gelants, both $\mathrm{Na}_{2} \mathrm{SO}_{3}$ and $\left(\mathrm{NH}_{2}\right)_{2} \mathrm{CS}$ are reducing agents (Zhao, 2003; Maxcy, 1998), they can reduce $\mathrm{Cr}(\mathrm{VI})$ of $\mathrm{Na}_{2} \mathrm{Cr}_{2} \mathrm{O}_{7}$ to $\mathrm{Cr}(\mathrm{III})$, that is:

$$
\begin{aligned}
& \mathrm{Cr}_{2} \mathrm{O}_{7}{ }^{2-}+3 \mathrm{SO}_{3}{ }^{2-}+8 \mathrm{H}^{+} \rightarrow 2 \mathrm{Cr}^{3+}+3 \mathrm{SO}_{4}{ }^{2-}+4 \mathrm{H}_{2} \mathrm{O} \\
& \mathrm{Cr}_{2} \mathrm{O}_{7}{ }^{2-}+6\left(\mathrm{NH}_{2}\right)_{2} \mathrm{CS}+8 \mathrm{H}^{+} \rightarrow 3\left(\mathrm{NH}_{2}\right)(\mathrm{NH}) \mathrm{CSSC}(\mathrm{NH})\left(\mathrm{NH}_{2}\right) \\
& +2 \mathrm{C}_{\mathrm{r}}^{3+}+7 \mathrm{H}_{2} \mathrm{O}
\end{aligned}
$$

Then the multi-core hydroxyl bridge ligand of $\mathrm{Cr}(\mathrm{III})$ was generated through hydrolysis action and hydroxyl bridge action, further hydrolysis action and hydroxyl bridge action:

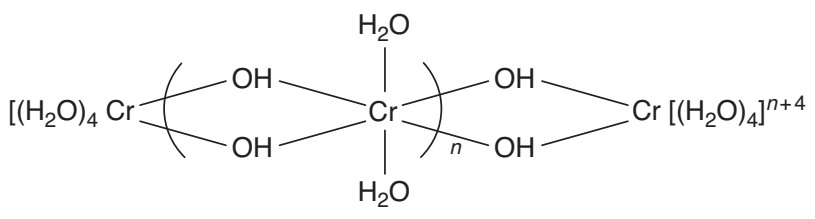

Then, the multi-core hydroxyl bridge ligand of $\mathrm{Cr}(\mathrm{III})$ crosslinked with carboxyl of HPAM to form bulk gel:

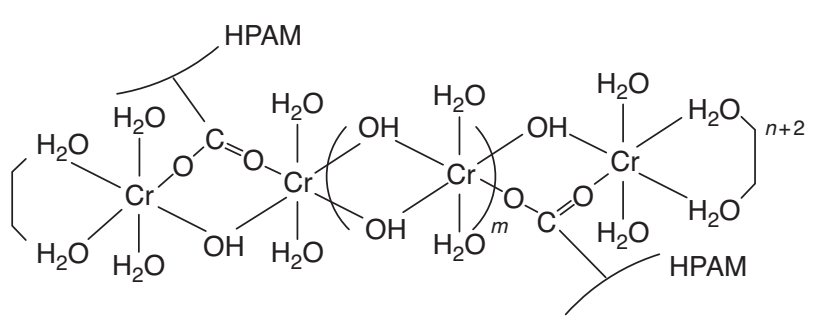

$\mathrm{S}$ is the most active part of the molecule of $\left(\mathrm{NH}_{2}\right)_{2} \mathrm{CS}$, which is a kind of organic matter. The reaction of $\left(\mathrm{NH}_{2}\right)_{2} \mathrm{CS}$ depends on the activity of $\mathrm{S}$. The carbon-sulfur double bond is a covalent one, and this covalent bond has to be destroyed during the reaction process. The reducibility of $\mathrm{Na}_{2} \mathrm{SO}_{3}$ is stronger than $\left(\mathrm{NH}_{2}\right)_{2} \mathrm{CS}$. Also, $\mathrm{Na}_{2} \mathrm{SO}_{3}$ can have a stabilizing effect on $\left(\mathrm{NH}_{2}\right)_{2} \mathrm{CS}$ (Liyuan Chai, 2002), and without $\mathrm{H}_{2} \mathrm{~S}$, the gelation time of $1^{\#}$ gelant is much shorter than that of $2^{\#}$ gelant.

$\mathrm{H}_{2} \mathrm{~S}$ is also a kind of reducing agent, and its reducibility is stronger than $\mathrm{Na}_{2} \mathrm{SO}_{3}$ and $\left(\mathrm{NH}_{2}\right)_{2} \mathrm{CS}$. When the concentration of $\mathrm{H}_{2} \mathrm{~S}$ is small in $1^{\#}$ and $2^{\#}$ gelants, $\mathrm{H}_{2} \mathrm{~S}$ will react with $\mathrm{Na}_{2} \mathrm{Cr}_{2} \mathrm{O}_{7}$ first, and the reaction velocity is faster than $\mathrm{Na}_{2} \mathrm{SO}_{3}$ and $\left(\mathrm{NH}_{2}\right)_{2} \mathrm{CS}$. Thus, the presence of $\mathrm{H}_{2} \mathrm{~S}$ decreases the gelation time of the two inorganic chromium crosslinking gelants. Further, because the reducing effect of $\mathrm{H}_{2} \mathrm{~S}$ is much stronger than $\left(\mathrm{NH}_{2}\right)_{2} \mathrm{CS}$, the gelation time of $2^{\#}$ gelant decreases more obviously. The shorter the gelation time is, the stronger the gel strength is (Caili Dai, 2001). So the gel strength increases when the concentration of $\mathrm{H}_{2} \mathrm{~S}$ increases, which is shown in Figure 4.

But when the concentration of $\mathrm{H}_{2} \mathrm{~S}$ reaches a certain value, the reduction reaction happens quickly. Redundant $\mathrm{Cr}$ (III) reacts with excessive $\mathrm{H}_{2} \mathrm{~S}$ and generates $\mathrm{Cr}_{2} \mathrm{~S}_{3}$ precipitation, and ultimately it can't form bulk gel.

The composition of the other systems named $3^{\#}$ and $4^{\#}$ is shown in Table 2. The following experiments where HPAM solution is replaced by the simulation water without this compound reconfirm the existence of the above precipitation reaction. The injection of $964 \mathrm{mg} / \mathrm{L}$ and $1083 \mathrm{mg} / \mathrm{L}$ concentrations of $\mathrm{H}_{2} \mathrm{~S}$ in $3^{\#}$ and $4^{\#}$ systems generates blue precipitation. The concentration of chromium and sulfur in the solution is measured before and after generation of the precipitate by ICP and the experimental result are shown in 
Table 3. We can see that the concentration of chromium and sulfur in the solution decrease obviously, so it confirms that most of chromium and sulfur have already formed the $\mathrm{Cr}_{2} \mathrm{~S}_{3}$ blue precipitation.

TABLE 3

Comparison of $\mathrm{Cr}$ concentration and $\mathrm{S}$ concentration before and after reaction

\begin{tabular}{c|c|c|c|c}
\hline Type of the gelants & \multicolumn{2}{|c|}{$3^{\#}$ gelant } & \multicolumn{2}{c}{$4^{\#}$ gelant } \\
\hline Elements & $\mathrm{Cr}$ & $\mathrm{S}$ & $\mathrm{Cr}$ & $\mathrm{S}$ \\
\hline Theoretical value (mg/L) & 793.9 & 1923.2 & 739.9 & 2703.5 \\
\hline Measured value (mg/L) & 5.75 & 1279.0 & 2.37 & 2164.0 \\
\hline
\end{tabular}

\subsection{The effect of $\mathrm{H}_{2} \mathrm{~S}$ on Organic Chromium Crosslinking Gelant}

The composition of the organic chromium crosslinking gelant for system $5^{\#}$ is reported in Table 2. Figure 6 and Figure 7 show the effect of $\mathrm{H}_{2} \mathrm{~S}$ on organic chromium crosslinking gel. The $X$ axis is $\mathrm{H}_{2} \mathrm{~S}$ concentration and the $Y$ is gelation time/gel strength. It can be seen that the gelation time prolonged and the gel strength slightly decreased.

The simulation produced water without HPAM is used in the test instead of HPAM solution. When adding $\mathrm{H}_{2} \mathrm{~S}$, there is no precipitation in $5^{\#}$ gelant. After a period of time, there is no change; during the opening of the bottle of $5^{\#}$ gelant, there is a strong smell of $\mathrm{H}_{2} \mathrm{~S}$. It is found that the concentration of sulfur in $\mathrm{H}_{2} \mathrm{~S}$ falls from $538 \mathrm{mg} / \mathrm{L}$ to $457 \mathrm{mg} / \mathrm{L}$. There is only a slight decrease (because of $\mathrm{H}_{2} \mathrm{~S}$ from the bottle to

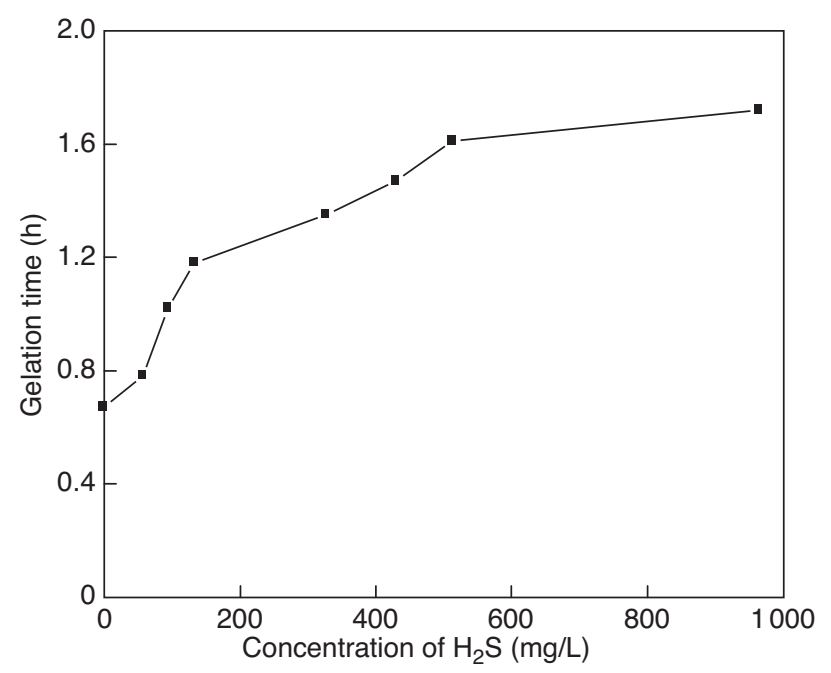

Figure 6

The effect of $\mathrm{H}_{2} \mathrm{~S}$ on the gelation time of $\mathrm{Cr}$ (III)-acetate \& Cr(III)-lactate/HPAM gel.

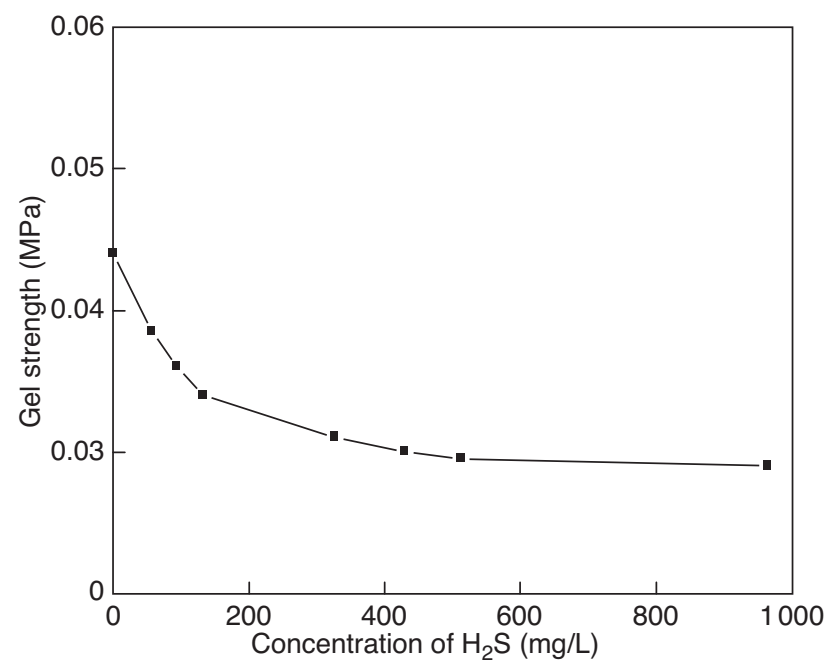

Figure 7

The effects of $\mathrm{H}_{2} \mathrm{~S}$ on the gel strength of $\mathrm{Cr}$ (III)-acetate \& $\mathrm{Cr}$ (III)-lactate/HPAM gel.

atmosphere as opening for examination the concentration of sulfur in $\mathrm{H}_{2} \mathrm{~S}$ ) which demonstrates that $\mathrm{H}_{2} \mathrm{~S}$ does not react with the organic chromium crosslinker.

$\mathrm{H}_{2} \mathrm{~S}$ is replaced by hydrochloric acid to comparatively study the influence of $\mathrm{pH}$ for $5^{\#}$ gelant. After adding hydrochloric acid instead of $\mathrm{H}_{2} \mathrm{~S}$, the gelation time is also prolonged and the gel strength is slightly decreased. It shows that the mechanism of $\mathrm{H}_{2} \mathrm{~S}$ affecting the organic chromium crosslinking gelant is different from that of the inorganic chromium crosslinking gelant. $\mathrm{H}_{2} \mathrm{~S}$ affects the organic chromium crosslinking gelant by changing $\mathrm{pH}$ value of the gelant. Figure 8 shows the influence of $\mathrm{H}_{2} \mathrm{~S}$ on the $\mathrm{pH}$ value of the produced water.

As shown in Figure 8, the $\mathrm{pH}$ value of the system becomes lower with the increase of the concentration of $\mathrm{H}_{2} \mathrm{~S}$; the influence of $\mathrm{H}_{2} \mathrm{~S}$ on $\mathrm{pH}$ value becomes also smaller with the increase of the concentration of $\mathrm{H}_{2} \mathrm{~S}$. Therefore, a low $\mathrm{H}_{2} \mathrm{~S}$ concentration has a large influence on the gelation time and the gel strength of the organic chromium crosslinking gelant. When the concentration of $\mathrm{H}_{2} \mathrm{~S}$ reaches a certain level, the influence becomes smaller.

YG107 crosslinker is a complex of $\mathrm{Cr}(\mathrm{III})$-acetate and $\mathrm{Cr}$ (III)-lactate. Lactic acid root and actate acid root reacts with $\mathrm{Cr}$ (III) by chelation which delay the crosslinking reaction of $\mathrm{Cr}$ (III) and polyacrylamide. The released $\mathrm{Cr}(\mathrm{III})$ should first be hydrolyzed into $\mathrm{Cr}\left(\mathrm{H}_{2} \mathrm{O}\right)_{6}$ (III), then through hydroxyl bridge action. Further hydrolysis action and hydroxyl bridge action, comes into a complexion of chromium which crosslinks with carboxyl of HPAM. 


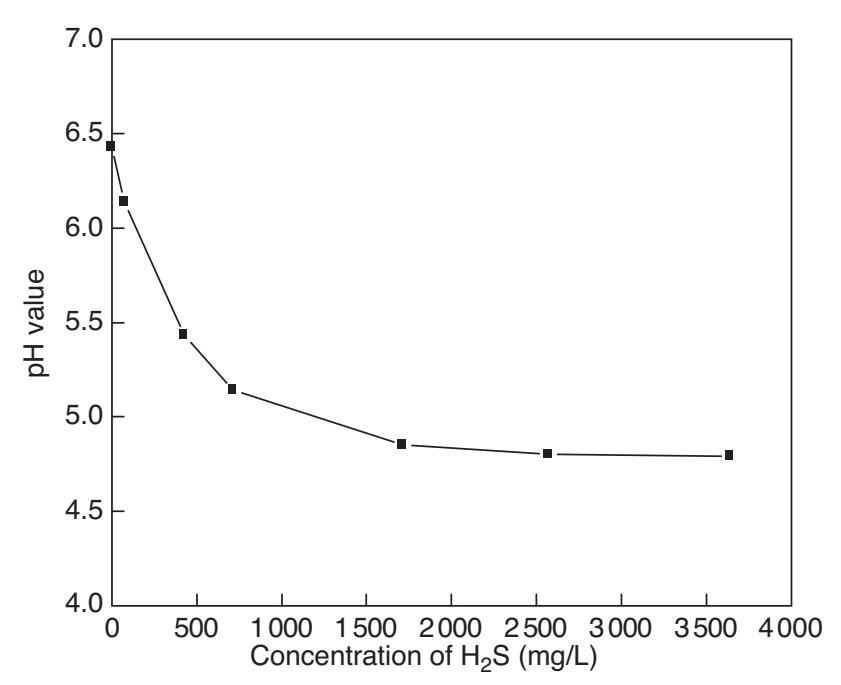

Figure 8

The $\mathrm{pH}$ value of the simulation produced water containing $\mathrm{H}_{2} \mathrm{~S}$.

The higher the $\mathrm{pH}$ is, the more easily HPAM gel forms and the better its stability is. The main reasons are:

- a high $\mathrm{pH}$ value is favorable for the hydrolysis of $\mathrm{Cr}(\mathrm{III})$. It helps to form gel;

- a high $\mathrm{pH}$ value is also favorable for the hydrolysis of amide and increasing charged groups of molecules. The increase of charged groups is beneficial to stretch the molecular chain, and then cross linking reaction is easy to happen. On the other hand, crosslinked junctions trend to increase, which increases the gel strength. Therefore, the injection of $\mathrm{H}_{2} \mathrm{~S}$ prolongs the gelation time and decreases the gel strength.

\subsection{The Effect of $\mathrm{H}_{2} \mathrm{~S}$ on Phenol Formaldehyde Resin/HPAM Crosslinking Gelant}

The composition of the phenol formaldehyde resin crosslinking gelant of system $6^{\#}$ is given in Table 2. Figure 9 and Figure 10 show that the results of $\mathrm{H}_{2} \mathrm{~S}$ on phenol formaldehyde resin crosslinking gel, the $X$ axis is $\mathrm{H}_{2} \mathrm{~S}$ concentration and the $Y$ is gelation time/gel strength. It can be seen that the gelation time is slightly prolonged and the gel strength slightly decreases, due to the effect of $\mathrm{H}_{2} \mathrm{~S}$.

YG103 is a phenol formaldehyde resin crosslinker, which is a water soluble resin and that is formed as the prepolymer of phenol and formaldehyde under catalyst with sodium hydroxide. It is also known as resol. Sodium hydroxide can not only have a strong catalysis effect on addition reaction between phenol and formaldehyde, but also improves the resol solubility in reaction medium.

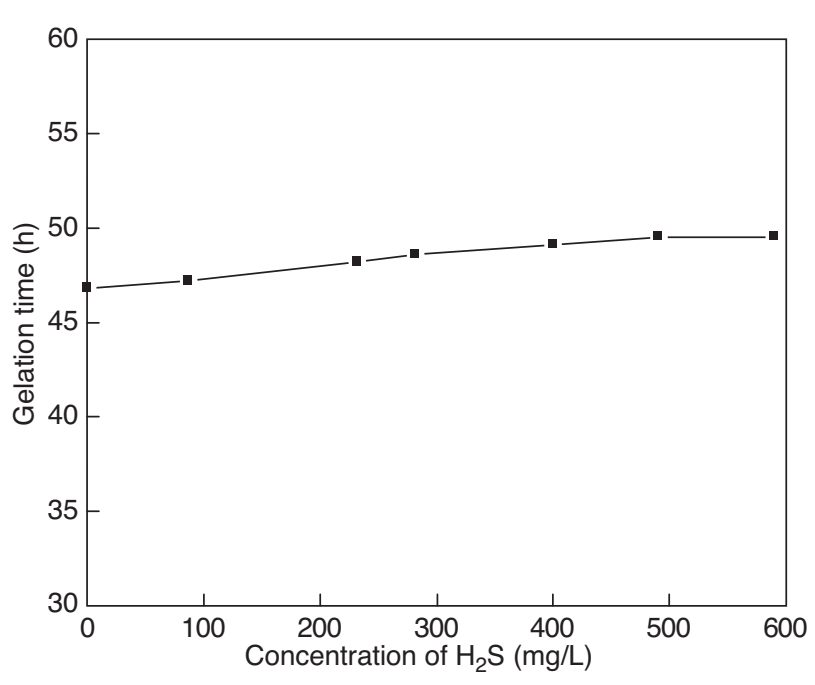

Figure 9

The effects of $\mathrm{H}_{2} \mathrm{~S}$ on the gelation time of phenol formaldehyde resin/HPAM gel.

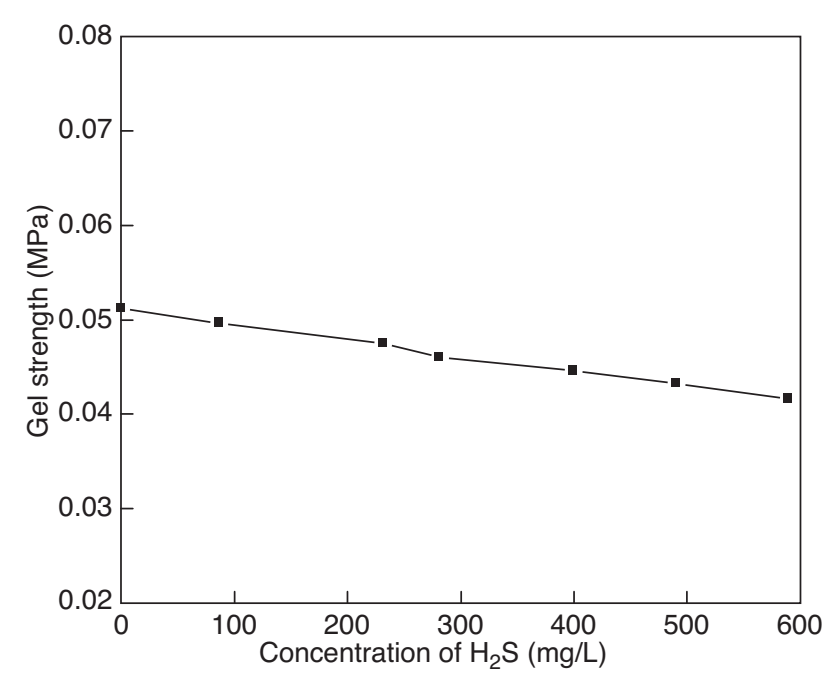

Figure 10

The effects of $\mathrm{H}_{2} \mathrm{~S}$ on the gel strength of phenol formaldehyde resin/HPAM gel.

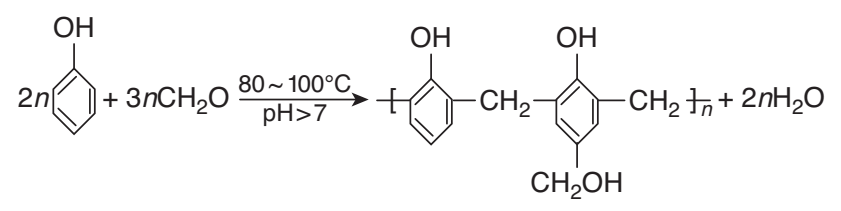

The crosslinking reaction between phenol formaldehyde resin and HPAM happens between hydroxymethyl of phenol formaldehyde resin and amide of HPAM. The more the numbers of hydroxymethyl functional groups are, the faster the crosslinking reaction is and the stronger the gel is. 
The addition of $\mathrm{H}_{2} \mathrm{~S}$ can reduce the rate of the crosslinking reaction by affecting the $\mathrm{pH}$ value of the gelant, but YG103 itself is a weak alkaline compound, and the phenolic hydroxyl group of YG103 can have certain buffering effects on the $\mathrm{pH}$ changes of the gelant. The effects of $\mathrm{H}_{2} \mathrm{~S}$ on the gelant of phenol formaldehyde resin/HPAM are relatively slight.

\section{CONCLUSIONS}

The effects of $\mathrm{H}_{2} \mathrm{~S}$ on the gels including $\mathrm{Na}_{2} \mathrm{Cr}_{2} \mathrm{O}_{7} /$ $\mathrm{Na}_{2} \mathrm{SO}_{3} / \mathrm{HPAM}$ gel, $\mathrm{Na}_{2} \mathrm{Cr}_{2} \mathrm{O}_{7} /\left(\mathrm{NH}_{2}\right)_{2} \mathrm{CS} / \mathrm{HPAM}$ gel, $\mathrm{Cr}$ (III)-acetate \& $\mathrm{Cr}$ (III)-lactate/HPAM gel and phenol formaldehyde resin/HPAM gel are studied in this paper. The effects of $\mathrm{H}_{2} \mathrm{~S}$ on $\mathrm{Na}_{2} \mathrm{Cr}_{2} \mathrm{O}_{7} / \mathrm{Na}_{2} \mathrm{SO}_{3} / \mathrm{HPAM}$ gel and $\mathrm{Na}_{2} \mathrm{Cr}_{2} \mathrm{O}_{7} /\left(\mathrm{NH}_{2}\right)_{2} \mathrm{CS} / \mathrm{HPAM}$ gels are dramatic. When the concentration of $\mathrm{H}_{2} \mathrm{~S}$ is less than $100 \mathrm{mg} / \mathrm{L}$, the gelation time decreases obviously with the increase of the concentration of $\mathrm{H}_{2} \mathrm{~S}$. The gel strength increases significantly; but, when the concentration of $\mathrm{H}_{2} \mathrm{~S}$ reaches a certain value, the gelants can not form bulk gel. With the increase of the concentration of $\mathrm{H}_{2} \mathrm{~S}$, for $\mathrm{Cr}(\mathrm{III})$-acetate \& $\mathrm{Cr}(\mathrm{III})$-lactate/HPAM gel, $\mathrm{H}_{2} \mathrm{~S}$ can prolong the gelation time and reduce the gel strength. For phenol formaldehyde resin/HPAM gel, $\mathrm{H}_{2} \mathrm{~S}$ can just slightly increase gelation time and decrease gel strength.

The mechanisms of actions of $\mathrm{H}_{2} \mathrm{~S}$ on the gels have also been studied. For $\mathrm{Na}_{2} \mathrm{Cr}_{2} \mathrm{O}_{7} / \mathrm{Na}_{2} \mathrm{SO}_{3} / \mathrm{HPAM}$ gel and $\mathrm{Na}_{2} \mathrm{Cr}_{2} \mathrm{O}_{7} /\left(\mathrm{NH}_{2}\right)_{2} \mathrm{CS} / \mathrm{HPAM}$ gel, as the reducer, $\mathrm{H}_{2} \mathrm{~S}$ can reduce $\mathrm{Cr}(\mathrm{VI})$ into $\mathrm{Cr}(\mathrm{III})$ and accelerate the reaction for low concentration of $\mathrm{H}_{2} \mathrm{~S}$, while it can react with $\mathrm{Cr}(\mathrm{III})$ and generate $\mathrm{Cr}_{2} \mathrm{~S}_{3}$ precipitation in high concentration of $\mathrm{H}_{2} \mathrm{~S}$, for which the bulk gel can not form without $\mathrm{Cr}$ (III). For $\mathrm{Cr}$ (III)acetate \& $\mathrm{Cr}$ (III)-lactate/HPAM gel and phenol formaldehyde resin/HPAM gel, $\mathrm{H}_{2} \mathrm{~S}$ can prolong the gelation time and reduce the gel strength by decreasing the $\mathrm{pH}$ value.
If the gelation time is too short, it is hard to control its application in oil and gas field. When the gel strength is too weak, the stability of gel is poor and a good water shutoff effect can not be achieved. Therefore, according to the comprehensive investigations of the effects of $\mathrm{H}_{2} \mathrm{~S}$ on gel as water shutoff agents, the phenol formaldehyde resin/HPAM gel is recommended as a water shutoff agent suitable for oil and gas reservoir containing $\mathrm{H}_{2} \mathrm{~S}$.

\section{REFERENCES}

1 Caili D., Guicai Z., Fulin Z. et al. (2001) Studies on influencing factors for formation of aqueous polyacrylamide/formaldehyde gel, J. Oilfield Chem. 18, 1, 26.

2 SY/T 5329-94 (1995) Chinese oil and gas industry standards the recommend water quality indication and methods of analysis of the clastic reservoir. 13-14.

3 Liyuan C., Xiaobo M. (2002) Structure-property relationship between the stability of alkaline thiourea and the structure of thiourea and sulfite ion, J. Cent. South Univ. Technol. (Natural Science) 33, 5, 473-476.

4 Jianjun W., Yan L., Qiang L. (2005) Application on sealing ability of new multi-functionial composite gel, J. Nature Gas Industry 25, 9, 101-103.

5 Jiyong Z., Xiangyi Y., Yuan L. (2005) Overview of drainage gas recovery technology at home and abroad, J. Taiyuan Univ. Technol. 36S, 44-45.

6 Xuejun Z., Ping'an D., Yimei W. (2003) Inorganic Chemistry, Wu Han University Press, Wu Han, pp. 354-355.

7 Xunyong N. (2006) The treatments of mud loss and blowing accidents in Kaixian Luojia Well 2 obtained great success, applying special gel sealing technology and products researched by Pingya Luo, academy of Southwest Petroleum University, $J$. Southwest Petroleum Institute 28, 2, 15.

8 Sydansk R.D. (1988) A New Conformance-ImprovementTreatment Chromium Gel Technology, SPE 17329. 106-112.

9 Maxcy T.A., Willhite G.P., Don W. Green (1998) A Kinetic Study of the Reduction of Chromium(VI) to Chromium(III) by Thiourea, J. Petrol. Sci. Eng. 19, 253-263.

Final manuscript received in March 2011 Published online in November 2011 